\title{
Health services to groups with special needs in the Arab world: a review
}

N.M. Kronfol

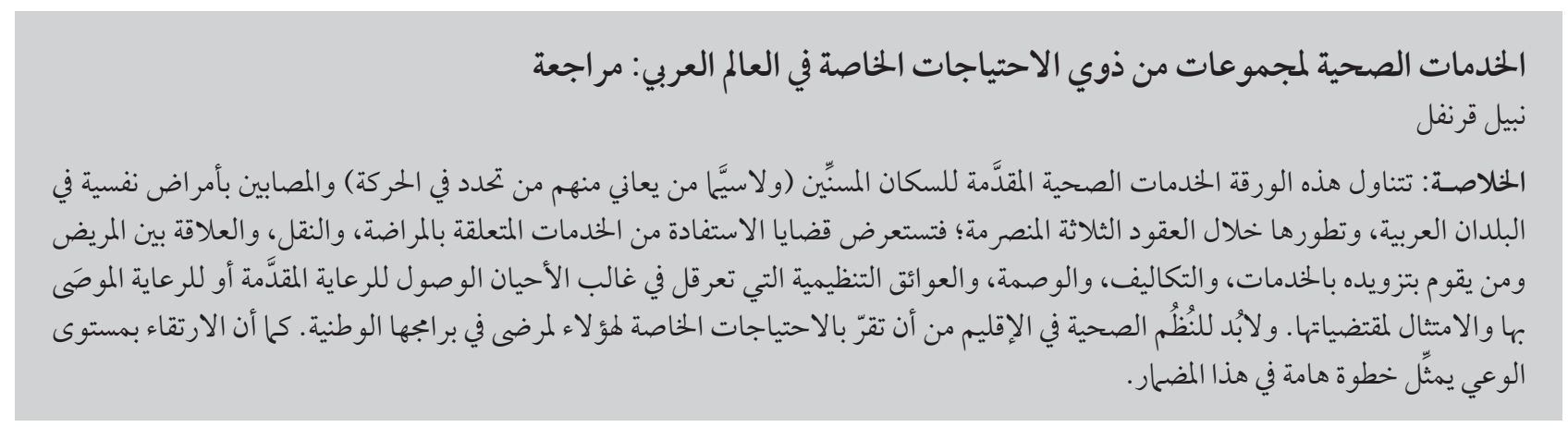

ABSTRACT This paper examines the health services provided to the older population (especially those with physical limitations) and the people with mental illnesses in Arab countries and their evolution over the past 3 decades. The paper reviews utilization issues related to morbidity, transportation, patient-provider relationship, cost, stigma and organizational barriers that often impede access and compliance with the care provided or recommended. Health systems in the region need to acknowledge the specific needs of these patients in their national programmes. Raising awareness is an important step in this regard.

\section{Services de santé aux groupes ayant des besoins particuliers dans le monde arabe : revue}

RÉSUMÉ Le présent article a examiné les services de santé fournis à la population de personnes âgées (en particulier celles affectées par des handicaps physiques) et aux personnes souffrant de maladies mentales dans les pays arabes, ainsi que leur évolution au cours des trente dernières années. La recherche a analysé l'utilisation des services en relation avec la morbidité, les transports, la relation patient-prestataire, le coût, la stigmatisation et les obstacles d'ordre organisationnel qui empêchent souvent l'accès aux soins fournis ou recommandés et leur observance. Les systèmes de santé dans la région doivent prendre en compte les besoins particuliers de ces patients dans leurs programmes nationaux. La sensibilisation est une étape importante à cet égard. 


\section{Introduction}

This paper is the last in a series of five reviews about the health services provided to groups with special needs in the Arab world [1-4]. The challenges faced by older people as well as people with functional and mental disabilities are highlighted. The purpose of this paper is to outline the needs of these special groups of citizens and to describe the barriers facing their access to care. It is important to note that access to health care for dependent older people in the Arab region is an area where there are many gaps in the available data.

\section{Older people with} functional limitations

Older people with functional limitations are defined here as people aged 65 or older with at least one restriction in their activities of daily living. These refer to mobility and self-care activities that a person must perform every day, such as bathing, dressing, eating, getting in and out of bed or chair, moving around, using the toilet and controlling bladder and bowel movements [5].

Older people face many challenges such as a greater need for services due to increased morbidity and disability, limited capacity to finance co-payments, hurdles of access to services due to mobility restrictions, limited health literacy and bureaucratic, fragmented service organization that can be aggravated by age discrimination in service provision [6]. The help-seeking behaviour of older people may be influenced by their expectations of health status as they get older [7]. Even where help is sought, the existence of many comorbidities may make it difficult for older people to get across their problems in the consultation setting [8]. There is evidence that older people and their informal carers try hard to maintain their identity as being healthy and fit despite having health problems, "managing" their health accordingly [9].
There have been very few studies in and around the Arab region about the utilization patterns of the elderly with functional impairment. In Israel researchers found that the predisposing and enabling factors were only minimally associated with utilization rates, except for lower rates of emergency room visits by those who were living alone. Health care utilization was found to be associated primarily with health needs and functional status rather than by factors such as income and education [10].

The health status, mental wellbeing and functional capacity of senior citizens (above 60 years of age) were assessed in Jordan. Of the 300 subjects enrolled, $53.3 \%$ were women, $74.4 \%$ were affected by chronic diseases, $24.3 \%$ were classified as depressed and $44.0 \%$ had a negative health perception. Women were more likely to be depressed and suffer memory impairment and limitation on functional capacity than did men. Depression, poor functional capacity and memory impairment reinforced each other, resulting in a state of dependency [11].

\section{Transport}

Older people with functional limitations face difficulties using public transport, going shopping, finding their way outside their home or even communicating over the phone [6]. This can severely limit their capacity to access health care services in a timely fashion. A study on the use of primary health care services and satisfaction by elderly people in Asir, Saudi Arabia reported that the 3 leading causes of dissatisfaction were poor transportation (65.1\%), long time spent in the centre (46.4\%) and insufficient specialty clinics (42.5\%) [12].

\section{Dependency}

Older people in the Arab region are living longer [13]. Improving health and social care for the growing number of older people with functional limitations who need constant support with basic activities of daily living should therefore be a major concern of both social and health policies in Arab countries.

Dependency in old age is usually defined by self-rated health status and functional status from survey data [6]. Subjective health status declines with age as it is linked to higher prevalence of chronic conditions and mental health problems [6]. Those affected by disability often suffer from several concurrent limitations such as visual impairment, hearing impairment and lower mobility [14]. These functional limitations put older people at risk of falls, injuries and accidents, social isolation and depression [15].

A study of 47 institutionalized older people in the United Arab Emirates (UAE) revealed that all except 1 had a neurological disorder and $89 \%$ had dementia. The cognitive deficits were severe, their functional status was poor and nutritional status was impaired. When compared with studies from the United States of America, this UAE group had a higher rate of neurological diseases and dementia, and were far more dependent and disoriented [14].

A psychosocial assessment of geriatric patients (65+ years) was carried out in Abha, Saudi Arabia. Depression was found in $17.5 \%$ of the subjects, more commonly in women than men ( $27.7 \%$ versus $12.7 \%$ ). The combined effect of impaired perceived health status $(52.4 \%)$ and functional capacity $(26.6 \%)$, loneliness $(4.5 \%)$, single status $(24.3 \%)$ and lack of education (80.5\%) explained the depression and the authors concluded that this needed to be addressed through periodic home psychosocial screening [15].

\section{Sociocultural factors}

Ethnicity plays a role as well in the status of older people. According to the Jewish-Arab Center at the University of Haifa, the percentage of Arab elderly who were disabled and need help with activities of daily living was twice as high as that of the Jewish elderly population 
[16]. The need for formal support systems services for the elderly with families is expected to increase markedly in the future. In addition, there is evidence that dependency in the Arab countries is more prevalent among people of lower socioeconomic status and lower educational attainment who are at higher risk at pension poverty [13]. This means that many dependent older people face the compounded risks of high health and social care needs and associated high costs.

\section{Health beliefs}

The help-seeking behaviour of older people seems to be influenced by their expectations of health status as they get older. There is some evidence that older people have substantially lower expectations regarding access and quality of services than younger people and they may be less critical about limitations and barriers in accessing the health care system $[6,11,12]$. They often seem to want to consult only if "really" necessary, rather than by right.

\section{Health problems}

Common health problems of older people are often not adequately addressed [17]. For example, deficits have been noted in the treatment of malnutrition, sleep disorders, depression, fall prevention and pain management [14]. Moreover, the mental health needs of older people are often neglected [15]. It seems that the interpretation of symptoms (both by patients and health professionals) as "age-related" may hide symptoms of real health problems that ought to be addressed and managed [18]. One of the difficulties in providing evidence of effectiveness of interventions in older groups is their exclusion from many clinical trial protocols.

\section{Age discrimination}

It is also often the case that health professionals seem to favour younger age groups that are perceived to benefit more from treatment [19]. For example, it has been reported that older people are less likely to be referred for surgery [20]. There is some evidence that old patients often receive less costly treatments than younger patients for the same conditions [21]. Evidence from Jordan suggests that many complications and worsening of health and disability status in old age would be preventable if adequate rehabilitative and preventative care were provided in a timely manner [17]. This includes care for incontinence, fall prevention, osteoporosis, depression and immunization against influenza. A study in Saudi Arabia examined the perception of participating physicians in hospital and primary health care on the nature of illness of elderly patients and the type of health professionals that should be involved in their care. Both primary health care doctors and hospital doctors gave priority to bedridden patients and lowest priority to mobile chronically ill patients. It was suggested that the number, qualifications and responsibilities of the various professionals involved in the care of older patients should be re-evaluated [22].

\section{Caregivers}

The majority of older persons in the Arab region live with their families, who provide the help and care required for relatives who are functionally impaired. Taking care of an older, impaired relative is considered a source of enrichment for the caregiver and an act of gratitude towards the older person. However, there are few formal resources to support these families. The situation of dependent older people rests very much on the important role played by informal care that is provided by family and friends, by the voluntary sector or by homehelp caregivers. A study from the Université Saint-Joseph in Lebanon, has reported that the informal emotional support received by caregivers is positively related to wellbeing, whereas interpersonal conflicts with family and friends diminish caregiver well-being and increase role strain [23].

\section{Organization}

There is a growing recognition that the complexity of the boundaries between health and social care, present important barriers for older people [24]. The main obstacles for implementing coordinated care in the region include insufficient public funding, unequal access, specific eligibility criteria and lack of overall responsibility for coordinated provision of care and services [13]. There are significant differences between the social and health care sectors, in areas such as qualifications, ways of working and systems and quality management [13]. Elderly patients were found to be more at risk of patient safety incidents than younger age groups and have the highest risk of dying from a patient safety incident [20]. An estimated $15 \%$ of the elderly receive inappropriate medications [25].

\section{Age discrimination}

Age discrimination in access to health services is emerging as a serious problem [25]. Access for dependent older people is negatively affected by the views and perceptions of health care practitioners [22]. The existence of this form of "ageism" needs to be addressed.

\section{Training in geriatric care}

It has been acknowledged that training in geriatrics and gerontology in the Arab region is less than optimal and needs to be strengthened [26]. Efforts have been expanded and developments in the area of education and training are forthcoming.

\section{Cost}

As frequent users of health care services, older people often have a high financial burden from the cost requirements of health care, both for essential services and for pharmaceuticals and other medical goods, such as 
glasses and hearing aids [27]. A systematic review examined the effectiveness of interventions led by pharmacists in reducing polypharmacy. The most frequently reported outcome related to cost savings [28]. In Israel, application of a geriatric-palliative methodology to combat polypharmacy yielded a number of benefits such as a reduction in mortality rates and referrals to acute care facilities, lower costs and improved quality of life [29].

Out-of-pocket payment for essential services that are not covered by the public system may contribute to this financial burden in the Arab region [27]. Although there is a trend of increasing life expectancy in the region, there is still much uncertainty about what proportion of the additional lifespan is lived with the burden of disability among elderly people.

\section{People with mental health problems}

People with mental health disorders have overlapping disadvantages. In principle, people with mental health disorders are entitled to the same spectrum of health services as ablebodied people. However, many Arab countries gear services towards the needs of people with physical illness [30].

Many people with mental health disorders are not active in working life, due to unemployment or disability. In countries with a health insurance system based on employment, people excluded from the labour market face difficulties in access to health care [24]. Mental health disorders are associated with poverty and low socioeconomic status [31]. For many people with mental health disorders the only available route to access general health care is therefore through public services. This leads to a more restrictive coverage than people who can afford to pay out-ofpocket for health services [32].

\section{Transport}

People with mental health disorders may be particularly disadvantaged by geographical barriers of access to health care because of difficulties in use of transportation [33].

\section{Morbidity}

A recent literature review relating to inequalities in health status among those with mental health problems reported the following findings [34]. There were higher mortality rates among those with mental health problems, even after accounting for deaths from suicide and higher than average rates of physical illness among people with mental health problems, including cardiovascular disease (ischaemic heart disease, stroke, hypertension), diabetes, respiratory disease; sexually transmitted diseases (HIV/AIDS and hepatitis B and C) and poor oral health. Cancer rates have generally been found to be similar to the rest of the population.

A review of the literature was carried out to draw up a profile of the situation for mental health services and research in the region, and to suggest some measures for intervention. Although there are 22 Arab countries in the Arab League, the mental health services provided in those countries exhibit several variations. Economic, political, social and cultural factors seem to play a major role in determining the state of the psychiatric profession and the access of the service to citizens. Some Arab countries enjoy the highest per capita income in the world, yet this is inconsistent with the quality of mental health services available there. The per capita mental health services, the availability of a Mental Health Act and the space allocated for mental health in medical curricula are but just some of the concerns that have been expressed by colleagues from the different countries of the Arab region [35].

Elsewhere in the Eastern Mediterranean Region, in the Islamic Republic of Iran, the most common barriers to the utilization of mental health services were logistic, especially the cost of and inconvenient access to services. Barriers related to perceptions of mental health services were also important, such as lack of trust and perceptions of friends/ family [36].

Depressive and adjustment disorders were the most often diagnosed psychiatric illnesses among inpatients referred for psychiatric consultation in Saudi Arabia [37]. Males were more frequently admitted for schizophrenia and females for mood and anxiety disorders. Most non-Arab expatriates were diagnosed with acute and transient psychotic, stress-related or dissociative disorders. Gender and immigration were the main determinants of variance in patient characteristics. Active family involvement improves compliance and might reduce re-hospitalization rates [38].

National hospitalization records from Israel revealed that Arab women utilized psychiatric services less than Arab men. The exact reverse occurred among Jewish patients. Moreover, Arab patients significantly underutilized mental health services, compared with Jewish patients. Possible reasons for these utilization patterns include: Arab health care utilization patterns in general; the availability of mental health services in Arab communities; the influence of the "cultural" over the "professional" in Arab mental health utilization; the lack of Arab mental health practitioners; Arab attitudes towards mental health; and gendered role constructs within Arab society. The findings emphasized the need for a policy of developing infrastructure and trained personnel who can provide services adapted to the special cultural characteristics of the Arab population [39].

\section{Stigma}

Stigma underlies many of the barriers to access, and is relatively well documented. A recent indepth review of 
the issues of stigma and discrimination faced by those with mental health problems concluded that on the basis of global evidence about stigma "there is no known country, society or culture in which people with mental illness are considered to have the same value and to be as acceptable as people who do not have mental illness" [40].

Health care for people with mental health disorders tends to be underfunded throughout the Arab region, which could be explained by stigma and discriminatory attitudes [33]. Evidence suggests that stigma lessens the responsiveness of the health services, and that the fear of being labelled may cause individuals with mental health problems to delay or avoid seeking treatment altogether [25]. Those already labelled by the health services may decide to distance themselves from the label, forgoing treatment or becoming noncompliant. There is evidence also that the responsiveness to physical health problems of people with mental health disorders is severely undermined by prejudices and discriminatory attitudes of health care staff $[41]$.

Self-stigmatization is also a factor, which in combination with previous bad experiences of health care (e.g. compulsory admissions or humiliating treatment), makes it difficult for the person with a mental health disorder to seek help and assert his/her rights to care [6]. Health staff may be more paternalistic and less likely to share decision-making than they would with patients without a mental disorder [41]. A paternalistic and derogatory health provider approach will add to previous disappointing encounters with the health system, and further decrease the user's incentives to seek help for health problems. Many health professionals also seem to have the false perception that achieving health and wellness is not feasible among people with mental health disorders [41].

\section{Cost}

Data indicates that mental health problems are associated with low socioeconomic status, including low income, unemployment and low education levels [35]. The ensuing poverty means that cost constitutes a particular barrier of access to health care for the group of people with mental health disorders.

\section{Organizational barriers}

Many general organizational barriers in access to health care, such as waiting lists, may constitute an even higher barrier for people with mental health disorders because of their lack of resources to enable them to utilize alternative pathways to care (e.g. private health care) [6]. Mental health disorders are also often correlated with poor health literacy [40].

Research from several countries and international studies indicate that physical and mental morbidity often go hand in hand [42]. Excess morbidity from physical disease may, in part, be related to common underlying factors. These include poverty, direct disease influence (e.g. depression leads to increased risk of cardiovascular disease), adverse treatment effects and unhealthy lifestyles. It is a challenge for general health services to recognize psychiatric comorbidity. Likewise, it is a challenge for mental health services to recognize physical comorbidity $[40,41]$.

Access to services may also be restricted if health care professionals believe that specific types of interventions are ineffective for people with mental health problems [41]. This may be particularly the case for health promotion and prevention therapies, where evidence of effectiveness is generally limited [41]. There may be a belief that people with mental health problems are even less amenable than other population groups to such interventions, because they are not good at adhering to long-term behaviour changes for example [40]. However, current evidence indicates that health promotion among people with mental disorders is feasible and effective [40].

In working to overcome these barriers, reports suggest that clinical practice guidelines are one useful tool to support the recognition of physical illness in people with mental health disorders [40]. It is reported that practice guidelines for mental health disorders incorporate recommendations to support improved recognition of physical comorbidity [41]. To ensure proper identification and treatment of physical diseases of people with mental health disorders, mental health care staff also need to be adequately trained.

\section{Coordination of care}

Evidence indicates that a general health policy supporting integration of health and social services and mainstreaming of mental health services will also offer better access to general health care [40]. There is also evidence that a multi-professional team-based approach is an effective method of providing services to deprived people with mental health disorders and complex problems [41].

Measures to improve the capacity of staff to recognize and treat physical and mental disorders are needed in the Arab region, as well as a radical change in the attitudes of staff of institutions is needed. Research suggests that the organization of services is the key to success in meeting the needs of people with mental health disorders, with integration, coordination, communication and seamless provision across health and social care sectors being of vital importance [40]. A transformation of the mental health care system towards a multidisciplinary, coordinated and holistic approach is required. It should be noted, however, there have been several recent reports on mental health in the Arab countries [43-55]. This trend highlights a change in attitudes among health professionals as well as the public concerning mental health and wellness. 


\section{Summary}

Governments in the Arab region need to acknowledge the specific needs of older people with impairments and people with mental health disorders and centrally target the needs of these groups in national health inequalities programmes, providing incentives to providers and managing performance to ensure targets are met. Specific treatment guidelines need to be developed where needed. Raising awareness the health needs of such groups is a crucial measure that ought to be undertaken in close collaboration with users' groups, civil society organizations and the media.

\section{References}

1. Kronfol NM. Historical development of health professions education in the Arab world: a review. Eastern Mediterranean Health Journal, 2012, 18:1157-1165.

2. Kronfol NM. Historical development of health systems in the Arab countries: a review. Eastern Mediterranean Health Journal, 2012, 18:1151-1157.

3. Kronfol NM. Delivery of health services in Arab countries: a review. Eastern Mediterranean Health Journal, 2012, 18:1229 1238.

4. Kronfol NM. Access and barriers to health care delivery in the Arab countries: a review. Eastern Mediterranean Health Journal, 2012, 18:1239-1246.

5. Long-term care for older people. Paris, Organisation for Economic Co-operation and Development, 2005.

6. Quality in and equality of access to healthcare services. Brussels, European Commission, Directorate-General for Employment, Social Affairs and Equal Opportunities, 2008.

7. Walters $\mathrm{K}$ et al. An exploration of help-seeking behaviour in older people with unmet needs. Family Practice, 2001, 18:277-282.

8. Dixon-Woods $\mathrm{M}$ et al. Vulnerable groups and access to health care: a critical interpretive review. Report for the National Coordinating Centre for NHS Service Delivery and Organisation $R$ $\& D$. London, National Coordinating Centre for NHS Service Delivery and Organisation, 2005.

9. Tanner D. Older people and access to care. British Journal of Social Work, 2003, 33:499-515.

10. Walter-Ginzburg A et al. Physicians visits, emergency room utilization and overnight hospitalization in the old-old in Israel: the cross sectional and longitudinal aging study (CALAS). Journal of the American Geriatrics Society, 2001, 49(5):549-556.

11. Youssef RM. Comprehensive health assessment of senior citizens in Al-Karak governorate, Jordan. Eastern Mediterranean Health Journal, 2005, 11:334-348.

12. Mahfouz AA et al. Primary health care services utilization and satisfaction among the elderly in Asir region, Saudi Arabia. Eastern Mediterranean Health Journal, 2004, 10:365-371.

13. Sibai A, Kronfol N. Situation analysis of population ageing in the Arab countries: the way forward towards implementation of MIPAA. Beirut Economic and Social Commission for Western Asia, 2008 (E/ESCWA/SDD/2008/Technical Paper.2).

14. Margolis SA, Reed RL. Institutionalized older adults in a health district in the United Arab Emirates: health status and utilization rate. Gerontology, 2001, 47:161-167.

15. Abolfotouh MA et al. Psychosocial assessment of geriatric subjects in Abha City, Saudi Arabia. Eastern Mediterranean Health Journal, 2001, 7:481-491.

16. Azaiza F, Brodsky J. The aging of Israel's Arab population: needs, existing responses, and dilemmas in the development of services for a society in transition. Israel Medical Association Journal, 2003, 5:383-386.
17. Youssef RM. Comprehensive health assessment of senior citizens in Al-Karak governorate, Jordan. Eastern Mediterranean Health Journal, 2005, 11:334-348.

18. Van der Wurff FB et al. Prevalence and risk-factors for depression in elderly Turkish and Moroccan immigrants in the Netherlands. Journal of Affective Disorders, 2004, 83:33-34.

19. Goddard M, Smith P. Equity of access to health care. York, England, University of York Centre for Health Economics, 1998 (Working Paper No. 32).

20. Uiters $\mathrm{E}$ et al. Use of health care services by ethnic minorities in The Netherlands: do patterns differ? European Journal of Public Health, 2006, 16:388-393.

21. Beech R. Chapter 5. Organisational barriers to access. In: Gulliford M, Morgan M, eds. Access to health care. London, Routledge, 2003:84-103.

22. Al Shammari SA. Home visits to elderly patients in Saudi Arabia. Journal of the Royal Society of Health, 1997, 117:174-179.

23. Séoud J et al. The health of family caregivers of older impaired persons in Lebanon: an interview survey. International Journal of Nursing Studies, 2007, 44:259-272.

24. The Madrid International Plan for Active Aging. Guiding framework and toolkit for practitioners and policymakers. New York, United Nations, 2002.

25. Link BG, Phelan JC. Stigma and its public health implications. Lancet, 2006, 367:528-529.

26. Overview of available data, research, policies and institutional arrangements relating to older persons-progress since Madrid. Report compiled in preparation for The State of the World's Older Persons 2012. New York, United Nations Population Fund and HelpAge International, 2011,

27. Kronfol $\mathrm{N}$ et al. Needs assessment of impairments and disabilities amongst casualties suffered in the July-August 2006 hostilities in war-affected areas of Lebanon. Beirut, Lebanon, World Health Organization Country Office, 2007.

28. Rollason V, Vogt N. Reduction of polypharmacy in the elderly: a systematic review of the role of the pharmacist. Drugs and Aging, 2003, 20:817-832.

29. Garfinkel D, Zur-Gil S, Ben-Israel J. The war against polypharmacy: a new cost-effective geriatric-palliative approach for improving drug therapy in disabled elderly people. Israel Medical Association Journal, 2007, 9:430-434.

30. Strategy for mental health and substance abuse in the Eastern Mediterranean Region 2012-2016. Technical paper presented at the fifty-eighth session of the Regional Committee for the Eastern Mediterranean. Agenda item 4(c). Cairo, World Health Organization Regional Office for the Eastern Mediterranean, 2011 (EM/RC58/5).

31. Kronfol N. Beyond reconstruction: a national strategy for health system development in Lebanon. Beirut, Ministry of Health Lebanon, World Bank and World Health Organization, 2006.

32. Maternal, child and adolescent mental health: challenges and strategic directions for the Eastern Mediterranean Region. Cairo, 
World Health Organization Regional Office for the Eastern Mediterranean, 2010.

33. Mental health systems in the Eastern Mediterranean Region. Report based on the WHO assessment instrument for mental health systems. Cairo, World Health Organization Regional Office for the Eastern Mediterranean, 2010 (EMRO Technical Publications Series No. 37).

34. Nocon A. Background evidence for the DRC's formal investigation into health inequalities experienced by people with learning disabilities and/or mental health problems. Stratford upon Avon, England, Disability Rights Commission, 2006.

35. Okasha A, Karam E. Mental health services and research in the Arab world. Acta Psychiatrica Scandinavica, 1998, 98:406-413.

36. Ghanizadeh A et al. Frequency of and barriers to utilization of mental health services in an Iranian population. Eastern Mediterranean Health Journal, 2008, 14:438-446.

37. Al Haidar FA. Inpatient child and adolescent psychiatric referrals in Saudi Arabia: clinical profiles and treatment. Eastern Mediterranean Health Journal, 2003, 9:996-1002.

38. AbuMadini MS, Rahim SI. Psychiatric admission in a genera hospital. Patients profile and patterns of service utilization over a decade. Saudi Medical Journal, 2002, 23:44-50.

39. Al-Krenawi A. Mental health service utilization among the Arabs in Israel. Social Work in Health Care, 2002, 35:577-589.

40. The World health report 2001. Mental health: new understanding, new hope. Geneva, World Health Organization, 2001.

41. Integrating mental health into primary care: a global perspective. Geneva, World Health Organization and World Organization of Family Doctors, 2008.

42. Thornicroft G. Actions speak louder: tackling discrimination against people with mental illness. London, Mental Health Foundation, 2006.

43. Abou-Saleh MT, Ghubash R, Daradkeh TK. Al Ain Community Psychiatric Survey. I. Prevalence and socio-demographic correlates. Social Psychiatry and Psychiatric Epidemiology, 2001, 36:20-28.

44. Noorbala AA et al. Mental health survey of the adult population in Iran. British Journal of Psychiatry, 2004, 184:70-73.
45. Iraq mental health survey 2006/7. Cairo, World Health Organization Regional Office fot the Eastern Mediterranean, 2009.

46. Gubash R, Hamdi E, Bebbington P. The Dubai community psychiatric survey: I. Prevalence and socio-demographic correlates. Social Psychiatry and Psychiatric Epidemiology, 1992, 27:53-61.

47. Daradkeh TK, Ghubash R, Abou-Saleh MT. Al Ain community survey of psychiatric morbidity II. Sex differences in the prevalence of depressive disorders. Journal of Affective Disorders, 2002, 72:167-176.

48. Ghanem $M$ et al. National survey of prevalence of mental disorders in Egypt: preliminary survey. Eastern Mediterranean Health Journal, 2009, 15:65-75.

49. Kadri $\mathrm{N}$ et al. Moroccan national study on prevalence of mental disorders: a community based epidemiological study. Actualites Psychiatriques, 2010, 121:71-74.

50. Al-Jawadi AA, Abdul-Rahman S. Prevalence of childhood and early adolescence mental health disorders among children attending primary health care centers in Mosul, Iraq: a crosssectional study. BMC Public Health, 2007, 7:274.

51. Razokhi AH et al. Mental health of Iraqi children. Lancet, 2006, 368:838-839.

52. Mousa Thabet AA, Vostaris P. Epidemiology of children's mental problems in Gaza Strip. Eastern Mediterranean Health Journal, 2001, 7:403-412.

53. Emmanuelle E. Trauma related psychological disorders among Palestinian children and adults in Gaza and West Bank. International Journal of Mental Health Systems, 2009, 3:21.

54. Scott KM et al. Depression-anxiety relationships with chronic physical conditions: Results from the World Mental Health surveys. Journal of Affective Disorders, 2007, 103:113-120.

55. Maternal, child and adolescent mental health: challenges and strategic directions for the Eastern Mediterranean Region. Cairo, World Health Organization Regional Office for the Eastern Mediterranean, 2010. 